\title{
Human neutrophil respiratory burst response to influenza $A$ virus occurs at an intracellular location
}

\author{
Misha Kazhdan, Mitchell R. White, Alfred I. Tauber, and Kevan L. Hartshorn \\ Departments of Medicine and Pathology, Boston University School of Medicine and Boston City Hospital, Boston, \\ Massachusetts
}

\begin{abstract}
We have studied in detail the in vitro interactions of influenza A viruses (IAVs) with human neutrophils to clarify why these cells become dysfunctional during IAV infection. Unosponized IAV elicited a respiratory burst response in neutrophils which, like that triggered by formylmethionyl-leucyl-phenylalanine (fMLP), involved mediation of signal-transducing GTP-binding proteins and tyrosine kinase activation. The IAV-induced response differed from that provoked by fMLP in that $\mathrm{H}_{2} \mathrm{O}_{2}$ was produced without concomitant $\mathrm{O}_{2}{ }^{-}$release. IAV also did not cause extracellular release of granule enzymes in cytochalasin B-treated neutrophils. Using chemiluminescence assays, the respiratory burst response to IAV was found to occur at an intracellular location. These findings may, in part, explain the anomalous nature of the respiratory burst response elicited by IAV and suggest strategies for determining the mechanism of IAV-induced neutrophil deactivation. J. Leukoc. Biol. 56: 59-64; 1994.
\end{abstract}

Key Words: influenza virus - neutrophils - chemiluminescence • respiratory burst $\cdot$ degranulation

\section{INTRODUCTION}

Our interest in studying the interactions of influenza A viruses (IAVs) with human neutrophils derives from the long-standing observation that IAV-infected subjects are prone to suffer bacterial superinfection. These superinfections represent the major cause of morbidity and mortality during IAV epidemics [1]. There is abundant evidence that an acquired phagocyte (both neutrophil and monocyte) functional defect resulting from IAV infection is an important contributory factor to these superinfections [1-3]. Depression of neutrophil functional responses can be reproduced in vitro by addition of IAV [4] or purified IAV hemagglutinin preparations [5]. In the process of studying the mechanisms of this IAV-induced depression, we observed that the virus acts as a neutrophil respiratory burst stimulant in its own right [6]. Neutrophil activation by IAV is unusual in that hydrogen peroxide $\left(\mathrm{H}_{2} \mathrm{O}_{2}\right)$ but no superoxide $\left(\mathrm{O}_{2}^{-}\right)$is formed [6-8]. The cellular signals that precede activation by IAV bear many similarities to those triggered by chemoattractants: inositol trisphosphate and phosphatidic acid are released, and an intracellular calcium $\left(\mathrm{Ca}_{\mathrm{i}}{ }^{2+}\right)$ rise, intracellular $\mathrm{pH}$ changes, and membrane depolarization occur [9]. The $\mathrm{H}_{2} \mathrm{O}_{2}, \mathrm{pH}$, and membrane potential responses are inhibited by protein kinase antagonists, suggesting that protein kinase activation plays a role in neutrophil activation by IAV. In contrast to chemoattractant activation, pertussis toxin has no inhibitory effect on IAV-induced activation events [6]. Activation by IAV is triggered by binding of the IAV hemagglutinin to the neutrophil surface possibly through a crosslinking mechanism [10], although the specific surface receptors involved are unknown. How these various events relate to neutrophil deactivation by IAV also remains to be established.

The ability of neutrophils to be activated by unoposonized IAV, and to adhere specifically to IAV-infected epithelia [11], suggests that these cells may play a role in the early phase of IAV containment in vivo. In fact, neutrophils predominate in the early inflammatory infiltrate in humans [12] and animals [13] infected with IAV. Indirect evidence suggests that these neutrophils do play a protective role in nonimmune hosts infected with IAV $[3,8]$.

In this study we address some of the major anomalous features of neutrophil activation by IAV. We provide further evidence of similarities between the signal transduction events triggered by IAV and IMLP and data which indicates that neutrophil activation events in response to IAV occur largely at an intracellular site.

\section{MATERIALS AND METHODS}

\section{Reagents}

Formylmethionyl-leucyl-phenylalanine (fMLP), cytochalasin B, phorbol 12-myristate, 13-acetate (PMA), horseradish peroxidase type II, scopoletin, luminol, catalase, 4-aminoantipyrine, superoxide dismutase, cytochrome $c$, Ficoll, dextran, sodium citrate, citric acid, GTP $\gamma$ S, and GDP $\beta$ S were purchased from Sigma Chemical Co. (St. Louis, MO). Hypaque was obtained from Winthrop Pharmaceuticals (Des Plaines, IL). Organic solvents were purchased from Fisher Scientific (Fair Lawn, NJ) and Dulbecco's phosphatebuffered saline (PBS) with $\mathrm{Ca}^{2+}$ or $\mathbf{M g}^{2+}$ or without $\mathrm{Ca}^{2+}$ or $\mathrm{Mg}^{2+}$ from Flow Laboratories (Costa Mesa, CA). Genistein was obtained from LY Services Corp. (Woburn, MA). Tumor necrosis factor $\alpha$ and interferon $\gamma$ were gifts of Genentech (San Francisco, CA), and granulocyte-macrophage colony-stimulating factor (GM-CSF) was a gift of ICN Immunobiologicals (Costa Mesa, CA).

\section{Virus preparation}

Influenza $\mathrm{A}$ virus strains $\mathrm{H} 3 \mathrm{~N} 2 \mathrm{~A} / \mathrm{Texas} / 77$ (Texas 77) and H3N3 A/Bangkok/79 (Bangkok 79) were grown in the chorioallantoic fluid of 10-day-old embryonated hens' eggs and purified on a discontinuous sucrose density gradient as

\footnotetext{
Abbreviations: CL, chemiluminescence; IAV, influenza A virus; $\mathrm{ALLP}$, formylmethionyl-leucyl-phenylalanine; GM-CSF, granulocyte-macrophage colony-stimulating factor; HAU, hemagglutination unit; MPO, myeloperoxidase; PBS, phosphate-buffered saline; PMA, phorbol myristate acetate; PT, pertussis toxin.

Reprint requests: Kevan L. Hartshorn, Boston University School of Medicine, 80 East Concord St., Boston, MA 02118.

Received December 13, 1993; accepted February 23, 1994.
} 
previously described [4]. Virus stock was measured by hemagglutination assay, and titers of 1:2000 through 1:32,000 (as indicated) hemagglutination units (HAU) were measured after samples were thawed from frozen storage at $-70^{\circ} \mathrm{C}$.

\section{Neutrophil preparation}

Neutrophils from healthy volunteer donors were isolated to $>95 \%$ purity as previously described using dextran precipitation, followed by a Ficoll-Hypaque gradient separation for removal of mononuclear cells and hypotonic lysis to eliminate contaminating erythrocytes [4]. Cell viability was $>98 \%$ as determined by trypan blue staining, and cells were used within five hours of isolation.

\section{Measurement of neutrophil activation}

$\mathrm{H}_{2} \mathrm{O}_{2}$ production was measured by the oxidation of scopoletin, and $\mathrm{O}_{2}^{-}$was assessed by continuous monitoring of the superoxide dismutase-inhibitable reduction of cytochrome $c$ [6]. For the $\mathrm{H}_{2} \mathrm{O}_{2}$ assay sodium azide (final concentration $50 \mu \mathrm{M}$ ) was added except where otherwise indicated (e.g., Table 3).

Neutrophil chemiluminescence (CL) responses were measured by two methods. In method I (used in experiments presented in Table 3 only), a 2-ml preparation of PBS containing $400 \mathrm{HAU} / \mathrm{ml}$ of Bangkok $79 \mathrm{IAV}$ or $2.5 \times 10^{-7} \mathrm{M}$ fMLP and $1.1 \times 10^{-5} \mathrm{M}$ luminol was incubated at $37^{\circ} \mathrm{C}$, followed by addition of $400 \mu l$ of PBS containing $4 \times 10^{6}$ neutrophils. This method was devised to mimic as closely as possible the conditions used in the $\mathrm{H}_{2} \mathrm{O}_{2}$ assay. Glass scintillation vials containing $900 \mu \mathrm{l}$ of $\mathrm{PBS}$ at $37^{\circ} \mathrm{C}$ were prepared in advance, and at 2-min intervals $100-\mu 1$ aliquots were removed from the mixture of neutrophils and IAV or fMLP, added to the glass vials, and counted in a TM Analytic Delta 300 beta counter for $30 \mathrm{~s}$. In method II, samples containing $9 \mathrm{ml}$ of PBS, $1.1 \times 10^{-5} \mathrm{M}$ luminol, and $100 \mathrm{HAU} / \mathrm{ml}$ of Texas 77 or Bangkok 79 IAV to which $10^{7}$ neutrophils were added, followed by incubation at $37^{\circ} \mathrm{C}$. One-milliliter aliquots of these samples were taken immediately after addition of cells and at 2-min intervals thereafter, placed in glass vials, and counted for $30 \mathrm{~s}$ in the beta counter. In certain experiments, $200 \mu \mathrm{g} / \mathrm{ml}$ catalase or $50 \mu \mathrm{M}$ sodium azide was incorporated (where indicated) into the reaction mixture of neutrophils with IMLP or IAV. This amount of catalase was employed after determining that it was sufficient to reduce by $>90 \%$ the $\mathrm{H}_{2} \mathrm{O}_{2}$ detectable by the scopoletin assay after addition of $\mathrm{MLP}$.

Neutrophil degranulation was assessed by measuring lysozyme or myeloperoxidase (MPO) release into the cell supernatant. The cells were first incubated with cytochalasin B $(5 \mu \mathrm{g} / \mathrm{ml})$ for $5 \mathrm{~min}$ followed by addition of IAV, $5 \times 10^{-7} \mathrm{M}$ fMLP, or control buffer and incubation for various periods of time (as indicated) at $37^{\circ} \mathrm{C}$. Lysozyme and MPO contents of cell supernatants and lysed cell pellets were determined using the Micrococcus lysodeikticus and 4-amino antipyrine assays as described [14]. The virus preparations did not interfere with detection of a standard lysozyme preparation. Results are expressed as the lysozyme or MPO activity detected in the supernatant divided by the total activity in the lysed cell pellet and supernatant $\times 100$.

\section{Electropermeabilization of neutrophils}

Electropermeabilization was performed in a manner similar to that reported by Therrien and Naccache [15]. Neutrophils were incubated in permeabilization buffer (PBS without added $\mathrm{Ca}^{2+}$ or $\mathrm{Mg}^{2+}$ but with $5 \mu \mathrm{M}$ glucose and $100 \mu \mathrm{M}$ ATP added) at a concentration of $10^{7}$ cells $/ \mathrm{ml}$ and exposed to a single 1.45-mV pulse of a Bio-Rad Gene Pulser (Bio-Rad, Richmond, CA) at a capacitance of $25 \mu \mathrm{FD}$. The cells were then placed on ice for $10 \mathrm{~min}$, followed by resuspension in PBS with $\mathrm{Ca}^{2+}$ and $\mathrm{Mg}^{2+}$ for $\mathrm{H}_{2} \mathrm{O}_{2}$ assay. Cells treated in this manner were $>90 \%$ positive for trypan blue uptake and no longer exhibited membrane depolarization in response to fMLP (data not shown). In some experiments, GDP $\beta S$ or GTP $\gamma \mathrm{S}$ (both at a final concentration of $50 \mu \mathrm{M}$ ) was added prior to permeabilization and this concentration was main-

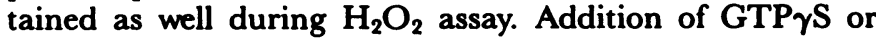
GDP $\beta S$ to nonpermeabilized neutrophils was not found to cause $\mathrm{H}_{2} \mathrm{O}_{2}$ production or alter responsiveness of the cells to other stimuli (data not shown).

\section{RESULTS}

\section{Role of GTP-binding proteins or tyrosine kinase activity in neutrophil respiratory burst activation by IAV or fMLP}

In the model of fMLP-induced neutrophil stimulation, activation of pertussis toxin (PT)-sensitive GTPbinding proteins precedes $\mathrm{Ca}^{2+}{ }_{i}$ mobilization. As noted above, however, neutrophil activation by IAV is insensitive to PT [6]. Cholera toxin does inhibit neutrophil $\mathrm{H}_{2} \mathrm{O}_{2}$ production and $\mathrm{Ca}^{2+}$ responses to IAV [6]; however, this effect could be secondary to cholera toxin-induced elevation of cAMP. We therefore sought another method of determining whether IAV interacts with neutrophil GTPbinding proteins. A protocol for electropermeabilization of neutrophils was developed which allowed continued detection of $\mathrm{H}_{2} \mathrm{O}_{2}$ production by virusstimulated cells despite rendering $>90 \%$ of the cells permeable to trypan blue. As depicted in Table $1, \mathrm{H}_{2} \mathrm{O}_{2}$ responses to IAV and IMLP were significantly inhibited in these cells when they were preincubated with GDPBS, whereas responses to PMA were unaffected. It was also possible to prime the $\mathrm{H}_{2} \mathrm{O}_{2}$ response to IAV and IMLP, but not PMA, by preincubation of the cells with substimulatory concentrations of GTPrS.

We have previously demonstrated that treatment of neutrophils with $\mathrm{H}-7$ or staurosporine inhibits $\mathrm{H}_{2} \mathrm{O}_{2}$ responses to IAV and fMLP in a similar manner $[7,9]$. Whereas both

TABLE 1. Effect of Guanine Nucleotides on $\mathrm{H}_{2} \mathrm{O}_{2}$ Responses of Electropermeabilized Neutrophils

\begin{tabular}{|c|c|c|c|c|}
\hline \multirow[b]{2}{*}{ Stimulus $^{b}$} & \multirow[b]{2}{*}{$n$} & \multicolumn{3}{|c|}{ Preincubation condition ${ }^{a}$} \\
\hline & & Control & GDPBS & GTP $\gamma$ \\
\hline IAV & 6 & $1.2 \pm 0.2$ & $0.6 \pm 0.15^{*}$ & \\
\hline IAV & 5 & $0.7 \pm 0.04$ & & $2.0 \pm 0.7^{*}$ \\
\hline FMLP & 8 & $1.0 \pm 0.2$ & $0.5 \pm 0.15^{*}$ & \\
\hline FMLP & 6 & $1.6 \pm 0.4$ & & $2.6 \pm 0.5^{*}$ \\
\hline PMA & 8 & $1.8 \pm 0.2$ & $1.7 \pm 0.16$ & \\
\hline PMA & 6 & $2.4 \pm 0.3$ & & $2.4 \pm 0.3$ \\
\hline
\end{tabular}

aNeutrophils were electropermeabilized as described in Methods in the presence of either control buffer or buffer containing $50 \mu \mathrm{M}$ GDPBS or GTP $\gamma \mathrm{S}$, followed by stimulation of $\mathrm{H}_{2} \mathrm{O}_{2}$ production (as measured by the scopoletin assay in presence of $50 \mu \mathrm{M}$ sodium azide) with IAV, IMLP, or PMA.

${ }^{b}$ Neutrophils were stimulated with either $200 \mathrm{HAU} / \mathrm{ml}$ Texas $77 \mathrm{IAV}, 10^{-7}$ $\mathrm{M}$ fMLP, or $250 \mathrm{ng} / \mathrm{ml}$ PMA and the maximal rate of $\mathrm{H}_{2} \mathrm{O}_{2}$ production (in $\mathrm{nmol} / 4 \times 10^{6}$ cells) over $3 \mathrm{~min}$ was calculated. GDP $\gamma \mathrm{S}$ significantly prolonged the lag period prior to onset of $\mathrm{H}_{2} \mathrm{O}_{2}$ production for all stimuli; GTP $\gamma \mathrm{S}$ did not consistently affect the lag period (data not shown). Guanine nucleotides did not significantly alter $\mathrm{H}_{2} \mathrm{O}_{2}$ responses to PMA.

$* P<.05$ compared with control. 
inhibitors may exert this effect by blunting protein kinase $\mathrm{C}$ activation, staurosporine also inhibits tyrosine kinases. Genistein inhibits tyrosine kinase activity with minimal effect on protein kinase $C$ [16]. As shown in Table 2, neutrophil $\mathrm{H}_{2} \mathrm{O}_{2}$ responses to IAV, fMLP, and PMA were significantly blunted by preincubation of the cells with $25 \mu \mathrm{g} / \mathrm{ml}$ genistein. Inhibition of IAV- and fMLP-induced responses was significantly greater than inhibition of those stimulated by PMA. [Chemiluminescence responses to IAV and fMLP were similarly inhibited by genistein (data not shown).]

\section{Lack of neutrophil degranulation in response to IAV}

As depicted in Figure 1, IAV did not elicit any detectable neutrophil degranulation as assessed by lysozyme release assay. This assay was done in the presence of cytochalasin $B$ (a maneuver that substantially increases neutrophil $\mathrm{H}_{2} \mathrm{O}_{2}$ responses to IAV [7]) to optimize granule enzyme detection. fMLP-treated cells exhibited substantial lysozyme release. Similarly, IAV did not provoke any MPO release from cytochalasin B-treated neutrophils, despite substantial release of this enzyme when the cells were stimulated with fMLP. MPO release after a 20-min incubation with Bangkok 79 IAV $(100 \mathrm{HAU} / \mathrm{ml}$ ) was $10 \pm 1 \%$ (not significantly different from the $6 \pm 3 \%$ release from neutrophils treated with buffer alone; mean \pm SEM, $n=3$ ). fMLP caused a $62 \pm$ $10 \%$ MPO release over the same time period $(P \leq .05$ compared with control).

\section{IAV-induced respiratory burst responses occur predominantly at an intracellular site}

We have previously reported that addition of azide significantly increases the $\mathrm{H}_{2} \mathrm{O}_{2}$ release that is detectable by the scopoletin assay after stimulation of neutrophils with IAV (but not with fMLP) [7]. This finding suggests that the respiratory burst response to IAV may occur predominantly at an intracellular location. According to this hypothesis $\mathrm{O}_{2}{ }^{-}$ is not detected because it cannot traverse the membrane, while $\mathrm{H}_{2} \mathrm{O}_{2}$ does. Azide increases the $\mathrm{H}_{2} \mathrm{O}_{2}$ escaping from the cell by diffusing into the cell and preventing metabolism of $\mathrm{H}_{2} \mathrm{O}_{2}$ by peroxidases or catalase. As shown in Table 3, when no azide was added to the assay, less $\mathrm{H}_{2} \mathrm{O}_{2}$ was detectable over $5 \mathrm{~min}$ in response to stimulation with the Bangkok 79 strain of IAV than was measured within $1 \mathrm{~min}$ in the presence of azide (see Table 2). However, a substantial

TABLE 2. Effect of Genistein on Neutrophil $\mathrm{H}_{2} \mathrm{O}_{2}$ Response to IAV or $\mathrm{AMLP}$

\begin{tabular}{lccc}
\hline Stimulus $^{a}$ & $\begin{array}{c}\text { Control } \\
\text { neutrophils }\end{array}$ & $\begin{array}{c}\text { Genistein-treated } \\
\text { neutrophils }^{b}\end{array}$ & \% of control \\
\hline fMLP & $1.41 \pm 0.28$ & $0.54 \pm 0.2$ & $45 \pm 6 \%(P \leq 0.005)$ \\
IAV & $0.43 \pm 0.08$ & $0.14 \pm 0.09$ & $20 \pm 6 \%(P \leq 0.01)$ \\
PMA & $2.32 \pm 0.25$ & $1.84 \pm 0.16$ & $80 \pm 3 \%(P \leq 0.025)$ \\
\hline
\end{tabular}

${ }^{a}$ The concentrations of MLP and PMA were same as in Table 1. For IAV, $100 \mathrm{HAU} / \mathrm{ml}$ of the Bangkok 79 strain was used.

${ }^{b}$ Neutrophils were pretreated with genistein $(100 \mu \mathrm{M}$ final concentration) or its diluent (control neutrophils) for $10 \mathrm{~min}$ at $37^{\circ} \mathrm{C}$, followed by resuspension in fresh buffer for measurement of $\mathrm{H}_{2} \mathrm{O}_{2}$ responses to stimulation with the indicated stimuli (as described for Table 1). Values given are mean \pm SEM $(n=4) \mathrm{H}_{2} \mathrm{O}_{2}$ produced over $1 \mathrm{~min}$ per $4 \times 10^{6}$ cells. All assays were carried out in the presence of $50 \mu \mathrm{M}$ sodium azide. To get \% of control, the response in genistein-treated neutrophils was divided by that in control neutrophils $\times 100$. Genistein reduced the response to all stimuli, but responses to IAV and AMLP were reduced significantly more than those to PMA $(P \leq .01)$.

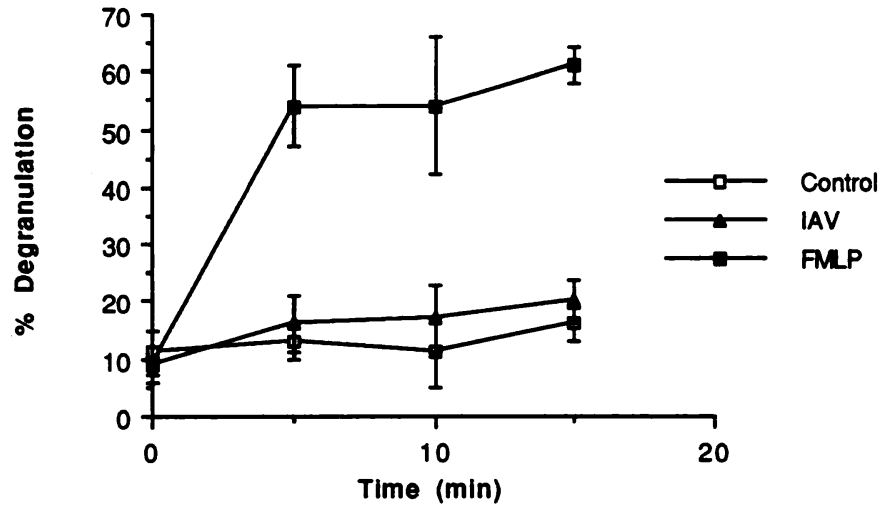

Fig. 1. Human neutrophil lysozyme release in response to IAV, fMLP, or control buffer. Lysozyme release from neutrophil granules was measuring using the Micrococcus lysodeikticus assay, as detailed in Methods. Mean \pm SEM of five experiments are shown. At time 0, IAV (400 HAU/ml Texas 77 IAV), IMLP $\left(10^{-7} \mathrm{M}\right)$, or control buffer was added to neutrophils maintained at $37^{\circ} \mathrm{C}$. Lysozyme measurements were made immediately after addition (time 0 ) and at 5, 10, and $15 \mathrm{~min}$. Degranulation was significantly greater $(P<.05)$ than the control value for $\mathrm{MLP}$ at 5,10 and $15 \mathrm{~min}$ but not for IAV at any time point.

chemiluminescence response was evident in the absence of azide as shown in Table 3. Note that the $\mathrm{CL}$ and $\mathrm{H}_{2} \mathrm{O}_{2}$ assays presented in Tables 2 and 3 were carried out under identical conditions (i.e., same concentrations of cells and virus) apart from the deletion of azide in the case of Table 3 . Hence, the $\mathrm{CL}$ assay is apparently more sensitive than the $\mathrm{H}_{2} \mathrm{O}_{2}$ assay for detecting a respiratory burst response to IAV. Since luminol can diffuse into neutrophils [17, 18], an intracellular response may be more evident on the CL assay. Alternatively, excitation of the IAV particle itself may contribute to the CL response [19]. Further assessment of oxidative metabolism was therefore sought.

To ascertain the amount of $\mathrm{H}_{2} \mathrm{O}_{2}$ released into the extracellular medium, in contrast to that remaining in the cell's interior, CL experiments were conducted with catalase, an enzyme too large for cellular incorporation. In preliminary experiments (data not shown) we determined that $200 \mu \mathrm{g} / \mathrm{ml}$ catalase fully inhibited the detection of $\mathrm{H}_{2} \mathrm{O}_{2}$ in response to either fMLP or IAV. In Figure 2, the effects of azide and catalase on CL generation in response to IAV or $\mathrm{AMLP}$ are shown. For these experiments (in contrast to those shown in Table 3), the mixture of neutrophils, luminol, and stimuli was not diluted at the time of scintillation counting (method II). This was done in an effort to maximize detection of an extracellular component of the CL response. Note that using this method, a substantial increase in light emission was detected in response to IAV compared with results shown in Table 3. Catalase did not significantly alter the CL response to IAV, although the CL response to $\mathrm{ALP}$ was markedly inhibited. As previously reported [20], the CL response to fMLP appears to consist of an early phase (from 1-4 min after stimulation) in which the CL is produced largely outside the cell, followed by a later phase in which intracellular CL production is more evident. The latter component of the fMLP response resembles that triggered by IAV. Azide essentially eliminated the CL response to both IAV and fMLP, as expected [19].

Preincubation of neutrophils with cytochalasin B has been found to enhance extracellular release of $\mathrm{O}_{2}{ }^{-}$in response to Histoplasma [21] or Neisseria gonorrhoeae [18]. This maneuver enhances the $\mathrm{H}_{2} \mathrm{O}_{2}$ response to $\mathrm{IAV}$, although not leading to any detectable $\mathrm{O}_{2}^{-}$release [6]. As shown in Figure 3, we tested the effect of cytochalasin B on the CL response to 
TABLE 3. Comparison of Neutrophil $\mathrm{H}_{2} \mathrm{O}_{2}$ and Chemiluminescence Responses upon Stimulation with IAV in Absence of Azide

\begin{tabular}{lcr}
\hline Response & Control buffer & \multicolumn{1}{c}{ IAV } \\
\hline $\mathrm{H}_{2} \mathrm{O}_{2}$ & $0.17 \pm 0.03$ & $0.30 \pm 0.03^{*}$ \\
$\mathrm{CL}$ & $408 \pm 155$ & $58,900 \pm 17,690^{*}$ \\
\hline
\end{tabular}

${ }^{a}$ Neutrophils were treated either with $100 \mathrm{HAU} / \mathrm{ml}$ Bangkok 79 IAV (as in Table 2) or control buffer and $\mathrm{H}_{2} \mathrm{O}_{2}(n=3)$ or chemiluminescence $(n=5)$ responses were measured using the scopoletin and luminol assays, respectively. No azide was added for these assays. The maximal CL response (in counts per $30 \mathrm{~s}$ ) was obtained at $5 \mathrm{~min}$ after addition of IAV or FMLP. The results given are mean \pm SEM counts/30 s taken at this time. The $\mathrm{H}_{2} \mathrm{O}_{2}$ results are mean \pm SEM produced over the first $5 \mathrm{~min}$ after addition of IAV. The CL assay for these experiments was performed using method I (see Methods).

$* P \leq .05$ compared with control response.

fMLP and IAV. The CL response to both stimuli was significantly enhanced by preincubation of neutrophils with cytochalasin B. In the case of fMLP this resulted in a much larger and more prolonged extracellular component of the CL response (as judged by the inhibitory effect of catalase). Again, however, catalase had no significant effect on the response to IAV.

We have previously reported that opsonization of IAV with the serum lectin mannose-binding protein (MBP) or conglutinin $[22,23]$ significantly enhanced the $\mathrm{H}_{2} \mathrm{O}_{2}$ (but not $\mathrm{O}_{2}{ }^{-}$) response to IAV. Similarly, preincubation of IAV with conglutinin significantly enhanced the CL response to IAV (mean CL response after $4 \mathrm{~min}$ was $91,250 \pm 47,524 \mathrm{cpm} / 30$ s for IAV alone vs. $231,000 \pm 94,249$ for IAV opsonized with $20 \mu \mathrm{g} / \mathrm{ml}$ conglutinin; $P \leq .05, n=4)$. Catalase did not significantly inhibit the CL response to IAV opsonized with conglutinin (data not shown). We also tested the ability of various priming agents including interferon- $\gamma$, tumor necrosis factor $\alpha$, and GM-CSF to enhance neutrophil CL responses to IAV. While preincubation of neutrophils with each of these agents increased the CL response to IAV, GMCSF was most potent in this regard, leading to a greater than tenfold enhancement of the CL response in four experiments (data not shown). Despite this, GM-CSF-treated neutrophils still did not release $\mathrm{O}_{2}^{-}$in response to the virus in three experiments.

Because these data indicate that the respiratory burst response to IAV occurs predominantly at an intracellular site, we tested whether electropermeabilized neutrophils can release $\mathrm{O}_{2}{ }^{-}$in response to IAV. Despite extensive permeabilization as assessed by trypan blue dye uptake, and substantial $\mathrm{H}_{2} \mathrm{O}_{2}$ production, no $\mathrm{O}_{2}^{-}$was detectable (data not shown).

\section{DISCUSSION}

Treatment of neutrophils with IAV leads to rapid and irreversible depression of the responses of these cells to subsequent stimulation with a variety of agonists [4]. This IAVinduced deactivation is characterized not only by impaired respiratory burst responses but also by impaired chemotaxis, degranulation, phagolysosome fusion, and bacterial killing $[1,2]$. In the process of studying the mechanisms of these deactivating effects of IAV, we noted that the virus in its own right caused activation of the neutrophil as assessed by a variety of assays $[4,6,7,9]$. Neutrophil stimulation by the virus was found to be anomalous in that a respiratory burst response was triggered in which $\mathrm{H}_{2} \mathrm{O}_{2}$, but no $\mathrm{O}_{2}{ }^{-}$, was released. Other features that distinguished the response to IAV from that to FMLP included (1) failure of pertussis toxin to inhibit responses to IAV and (2) an intracellular calcium response mainly derived from release of calcium from intracellular stores. We have attempted to further characterize the distinctive features of IAV's interactions with the neutrophil with the ultimate goal of clarifying why the virus depresses neutrophil function. Other neutrophil stimuli, including fMLP and concanavalin A, do not cause similar depression ([5] and our unpublished data).

As noted, one feature of neutrophil activation by IAV that is distinctive from stimulation by chemoattractants is the insensitivity of the former to pertussis toxin. Despite this difference, the findings reported in this paper suggest that ac-
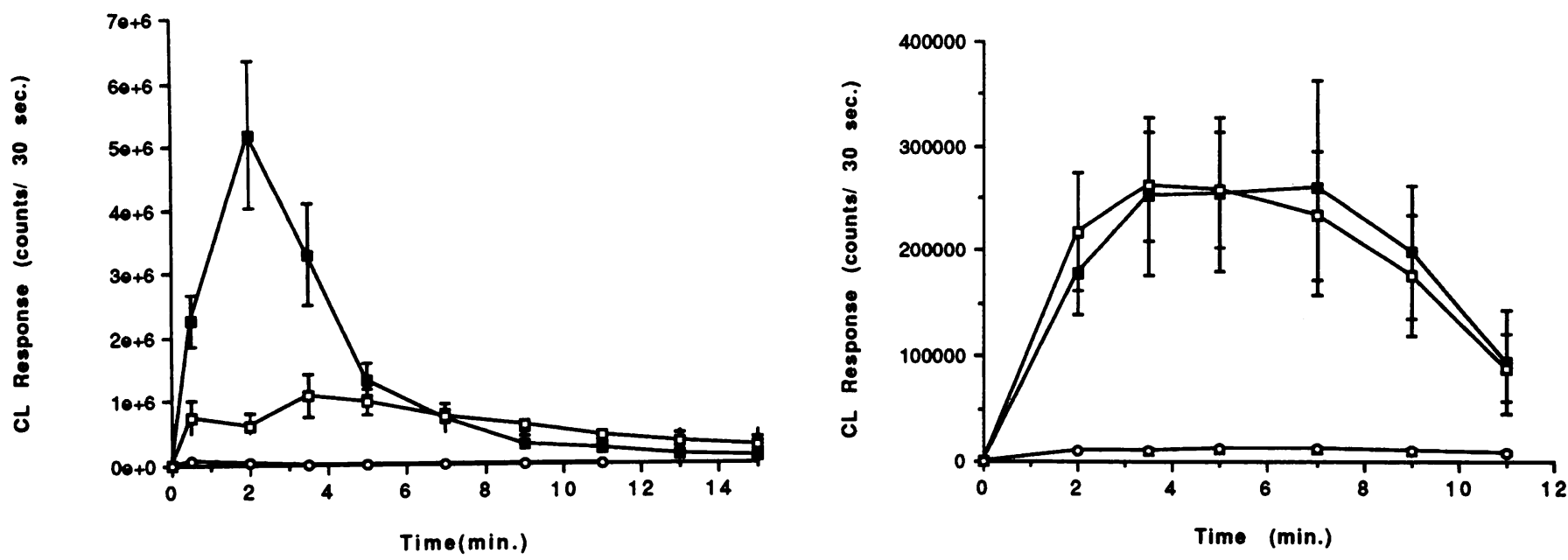

Fig. 2. Effect of catalase on neutrophil chemiluminescence responses to fMLP (left) or IAV (right). Neutrophils (107 cells in $10 \mathrm{ml}$ ) were treated with either $100 \mathrm{HAU} / \mathrm{ml}$ Bangkok $79 \mathrm{IAV}$ or $2.5 \times 10^{-7} \mathrm{M} \mathrm{fMLP}$ at time zero in the presence of luminol $\left(1.1 \times 10^{-5} \mathrm{M}\right)$. At the time points indicated, 1-ml aliquots of these stimulated neutrophil preparations (containing $10^{5}$ neutrophils $/ \mathrm{ml}$ ) were tested for light emission by scintillation counting (method II). Results represent mean $\pm \operatorname{SEM}(n=5$ except for assays in sodium azide, where $n=3)$. Open squares indicate duplicate runs of these assays in which $200 \mu \mathrm{g} / \mathrm{ml}$ catalase (final concentration) was incorporated into the buffers. Catalase significantly reduced the CL produced between 1 and 4 min after fMLP exposure $(P \leq .05$ ), but had no significant effect on the response to IAV. Azide (final concentration $50 \mu \mathrm{M}$ ) essentially eliminated the CL response to either fMLP or IAV (open circles). 

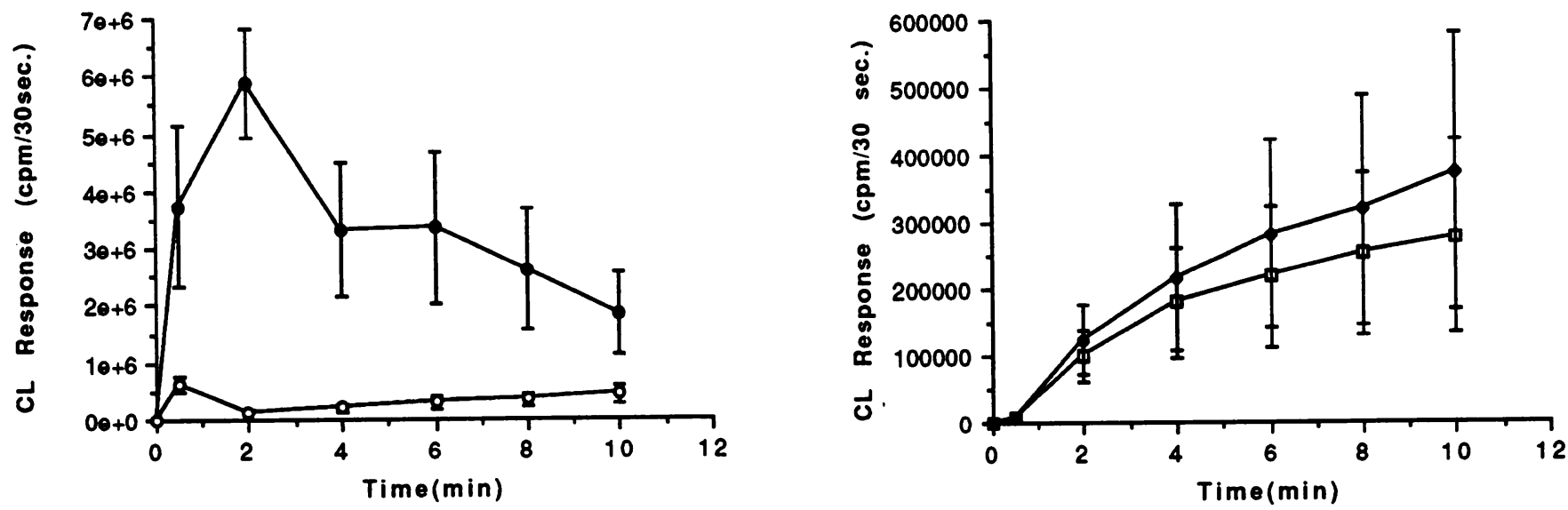

Fig. 3. Effect of catalase on chemiluminescence response to fMLP (left) or IAV (right) in cytochalasin B-treated neutrophils. The assay was performed as described in the legend of Figure 2 with the exceptions that neutrophils were pretreated for 5 min with $5 \mu \mathrm{g} / \mathrm{ml}$ cytochalasin B prior to stimulation with fMLP or IAV, and neutrophils were stimulated with 50 (rather than 100) HAU/ml IAV. Means \pm SEM of four or five experiments are shown. Concurrent assays were performed in the absence of cytochalasin B (not shown). Cytochalasin B significantly increased the CL response to both IAV and $\mathrm{fMLP}$ $(P \leq .05)$. Catalase significantly reduced $(P \leq .05)$ the $C L$ response to fMLP at all time points studied but had no significant effect on the response to IAV.

tivation of the neutrophil respiratory burst response by IAV does involve mediation of GTP-binding proteins. This conclusion is based on the inhibitory or enhancing effects, respectively, of GDP $\beta S$ or GTP $\gamma \mathrm{S}$ in electropermeabilized cells. Although one could argue that these guanine nucleotides are not necessarily acting on receptor-associated signaltransducing $G$ proteins but possibly on low-molecularweight proteins directly associated with NADPH oxidase assembly, this appears unlikely because responses to PMA were unaffected, while those to IMLP and IAV were altered in a very similar manner. The relatively gentle permeabilization procedure we employed may have allowed only limited penetration of guanine nucleotides into the cell so that only GTP-binding proteins associated with the plasma membrane were significantly affected. The identity of membrane receptor sites for IAV and which (possibly distinctive) GTPbinding proteins these receptors are associated with are important topics for future study.

Respiratory burst responses to IAV and fMLP were similarly reduced by the tyrosine kinase inhibitor genistein. Taking these findings in conjunction with our prior data, many similarities emerge in the post-G protein signal transduction cascade elicited by IAV and fMLP. On the other hand, the stoichiometry of the respiratory burst response to IAV is clearly distinctive from that to fMLP. We believe this discrepancy may provide clues to IAV-induced deactivation. We report here that treatment of neutrophils with IAV fails to cause any extracellular release of either lysozyme (a component of both specific and azurophilic granules) or myeloperoxidase (a component of azurophilic granules). Suchard et al. [24] have reported that exocytosis of a distinct population of lactoferrin-containing specific granules is a prerequisite for $\mathrm{H}_{2} \mathrm{O}_{2}$ production by adherent neutrophils. It remains possible such a population of granules is mobilized in IAVtreated neutrophils.

Using the CL assay, we also show that the respiratory burst response to IAV occurs largely at an intracellular site. The CL assay is capable of detecting respiratory burst products generated in the cell's interior, but the $\mathrm{H}_{2} \mathrm{O}_{2}$ assay is not. The marked increase in sensitivity of the $\mathrm{CL}$ assay compared with the $\mathrm{H}_{2} \mathrm{O}_{2}$ assay for detecting an IAV-induced respiratory burst response in the absence of azide provided an initial indication that this response occurs largely at an intracellular site. The marked inhibitory effect of azide on IAV-induced CL responses (as well as its enhancing effect of
$\mathrm{H}_{2} \mathrm{O}_{2}$ responses) suggested that an intracellular peroxidase was involved in catalyzing respiratory burst products generated by IAV in neutrophils. An alternative explanation of the discrepancy between results of these $\mathrm{CL}$ and $\mathrm{H}_{2} \mathrm{O}_{2}$ assays was that ingested IAV particles themselves participated in light emission in a manner akin to excitation of ingested zymosan [19]. This appears unlikely in view of the marked inhibitory effect of azide on the CL response to IAV. However, it remains possible that part of inhibitory effect of azide in this system results from effects on viral membrane fluidity (e.g., resulting in reduced light emission from IAV particles) rather than from inhibition of peroxidases. We, therefore, proceeded to demonstrate that the IAV-induced CL response occurs predominantly at an intracellular site by use of catalase. This enzyme is too large to gain access to the cell's interior and hence inhibits CL production only outside the cell $[17,18]$. Even when we used neutrophils pretreated with cytochalasin B, no inhibitory effect of catalase on IAVinduced CL responses was found.

Maneuvers that substantially increase the intensity of the neutrophil $\mathrm{H}_{2} \mathrm{O}_{2}$ or CL response to IAV (e.g., opsonization with conglutinin or priming of cells with GM-CSF) do not lead to generation of $\mathrm{O}_{2}^{-}$. Hence, the failure to detect $\mathrm{O}_{2}^{-}$is not likely to be due to lower sensitivity of the $\mathrm{O}_{2}^{-}$assay. We have also previously shown that IAV does not quench $\mathrm{O}_{2}^{-}$ [25].

We cannot conclude, however, that intracellular respiratory burst activation provides the entire explanation for the failure of IAV to trigger $\mathrm{O}_{2}^{-}$release, because electropermeabilized neutrophils also did not release $\mathrm{O}_{2}^{-}$upon stimulation with IAV. It remains theoretically possible that IAV triggers $\mathrm{H}_{2} \mathrm{O}_{2}$ production directly without intermediate production of $\mathrm{O}_{2}^{-}$. Further studies with cell-free NADPH oxidase preparations may help to resolve this issue. However, given the strong similarities in signals elicited by IAV and fMLP, it appears unlikely that a qualitatively different oxidase activity is involved. One intriguing possibility is that the virus binds directly to and perturbs membrane sites closely associated with, or actually including components of, the NADPH oxidase itself.

We conclude from these studies that determination of the mechanism through which IAV causes neutrophil deactivation could most profitably be achieved by (1) more direct studies of neutrophil surface binding sites for the IAV hemagglutinin molecule and (2) establishment of how, and 
into which compartments, IAV is internalized. Characterization of which $G$ proteins are involved in IAV-induced stimulation and the manner in which they are activated may also be revealing. However, IAV-induced neutrophil deactivation affects responses to PMA as much as to other stimuli [4]. Therefore, deactivation is unlikely to be attributable mainly to alterations in membrane receptor-associated $G$ proteins.

\section{ACKNOWLEDGMENT}

Supported by National Institutes of Health grants AI29550-03 (K.L.H.) and HL335565-08 (A.I.T.).

\section{REFERENCES}

1. Hartshorn, K.L., Tauber, A.I. (1988) The influenza virusinfected phagocyte: a model of deactivation. Hematol. Oncol. Clin. North Am. 2, 301.

2. Abramson, J.S., Mills, E.L. (1988) Depression of neutrophil function induced by viruses and its role in secondary microbial infections. Rev. Infect. Dis. 10, 326.

3. Hartshorn, K.L., Daigneault, D.E., Tauber, A.I. (1992) Phagocyte responses to viral infection. In Inflammation: Basic Principles and Clinical Correlates (J.I. Gallin, I.M. Goldstein, and R. Snyderman, eds) Raven Press, New York, 1017.

4. Hartshorn, K.L., Collamer, M., Auerbach, M., Myers, J.B., Pavlotsky, N., Tauber, A.I. (1988) Effects of influenza A virus on human neutrophil calcium metabolism. J. Immunol. 141, 1295.

5. Cassidy, L.F., Lyles, D.S., Abramson, J.S. (1989) Depression of polymorphonuclear leukocyte functions by purified influenza virus hemagglutinin and sialic acid-binding lectins. J. Immunol. 142, 4401.

6. Hartshorn, K.L., Collamer, M., White, M.R., Schwartz, J.H., Tauber, A.I. (1990) Characterization of influenza A virus activation of the human neutrophil. Blood 75, 218.

7. Hartshorn, K.L., Daigneault, D.E., White, M.R., Tuvin, M., Tauber, J.L., Tauber, A.I. (1992) Comparison of influenza A virus and formyl-methionyl-leucyl-phenylalanine activation of the human neutrophil. Blood 79, 1049.

8. Hartshorn, K.L., Karnad, A.B., Tauber, A.I. (1990) Influenza $A$ virus and the neutrophil: a model of natural immunity. J. Leukoc. Biol. 47, 176.

9. Hartshorn, K.L., Wright, J., Collamer, M., White, M.R., Tauber, A.I. (1990) Human neutrophil stimulation by influenza virus: relationship of cytoplasmic $\mathrm{pH}$ changes to cell activation. Am. J. Physiol. 258, C1070.

10. Daigneault, D.E., Hartshorn, K.L., Liou, L.S., Abbruzzi,
G.M., White, M.R., Oh, S.K., Tauber, A.I. (1992) Influenza A virus binding to human neutrophils and cross-linking requirements for activation. Blood 80, 3227.

11. Ratcliffe, D.R., Nolin, S.L., Cramer, E.B. (1988) Neutrophil interaction with influenza-infected epithelial cells. Blood 72, 142.

12. Sweet, C., Smith, H. (1980) Pathogenicity of influenza virus. Microbiol. Rev. 44, 303.

13. Smith, H., Sweet, C. (1988) Lessons for human influenza from pathogenicity studies with ferrets. Rev. Infect. Dis. 10, 56.

14. Metcalf, J.A., Gallin, J.I., Nauseef, W.M., Root, R.R. (1986) Laboratory Manual of Neutrophil Function. Raven Press, New York, 1986.

15. Therrien, S., Naccache, P.H. (1989) Guanine nucleotideinduced polymerization of actin in electropermeabilized human neutrophils. J. Cell Biol. 109, 1125.

16. Akiyama, T., Ishida, J., Nakagawa, S., Ogawara, H., Watanabe, S., Itoh, N., Shibuya, M., Fukami, Y. (1987) Genistein, a specific inhibitor of tyrosine specific protein kinases. J. Biol. Chem. 262, 5592.

17. Mundi, H., Bhorksten, B., Svanborg, C., Ohman, L., Dahlgren, C. (1991) Extracellular release of reactive oxygen species from human neutrophils upon interaction with Escherichia coli strains causing renal scarring. Infect. Immun. 59, 4168.

18. Naids, F.E., Rest, R.F. (1991) Stimulation of human neutrophil oxidative metabolism by nonopsonized Neisseria gonorrhoeae. Infect. Immun. 59, 4383.

19. Rosen, H., Klebanoff, S.J. (1976) Chemiluminescence and superoxide production by myeloperoxidase deficient leukocytes. J. Clin. Invest. 58, 50.

20. Briheim, G., Stendahl, O., Dahlgren, C. (1984) Intra- and extracellular events in luminol-dependent chemiluminescence of polymorphonuclear leukocytes. Infect. Immun. 45, 1.

21. Schnur, R.A., Newman, S.L. (1990) The respiratory burst response to Histoplasma capsulatum by human neutrophils. J. Immunol. 144, 4765.

22. Hartshorn, K.L., Sastry, K., White, M.R., Anders, E.M., Super, M., Ezekowitz, R.A., Tauber, A.I. (1993) Human mannose-binding protein functions as an opsonin for influenza A viruses. J. Clin. Invest. 91, 1414.

23. Hartshorn, K.L., Sastry, K., Brown, D., White, M.R., Okarma, T., Lee, Y., Tauber, A.I. (1993) Conglutinin acts as an opsonin for influenza A viruses. J. Immunol. 151, 6265.

24. Suchard, S.J., Burton, M.J., Boxer, L.A. (1994) The release of a specific subpopulation of specific granules coincides with $\mathrm{H}_{2} \mathrm{O}_{2}$ production in adherent human neutrophils. J. Immunol. $152,290$.

25. Hartshorn, K.L., Daigneault, D.E., White, M.R., Tauber, A.I. (1992) Anomalous features of human neutrophil activation by influenza $A$ virus are shared by related viruses and sialic acid-binding lectins. J. Leukoc. Biol. 51, 230. 